\title{
The Corneal Mucopolysaccharide
}

\author{
By A. M. WOODIN \\ Ophthalmological Research Unit (Medical Research Council) \\ Institute of Ophthalmology, London, W.C. 1
}

(Received 18 August 1951)

The acid mucopolysaccharide of cornea is present in the ground substance between the collagen fibres of the stroma. Although the presence of such a substance has been known since the work of Morner (1894) its chemical nature has been the subject of much discussion and the relation between the mucopolysaccharide and the collagen fibres has not been considered. Such information is of value for many reasons, amongst which can be mentioned the control of the permeability of the stroma, and the possible dependence of the transparency of the tissue on the relation between the mucopolysaccharide and the collagen fibres.

Meyer \& Chaffee (1940), who summarized the earlier work on the corneal mucopolysaccharide, obtained a protein-free preparation from an extract of the water-insoluble residues of cornea. This preparation gave positive reactions for a uronic acid, for acetyl groups, and for ester-S; glucosamine hydrochloride was isolated from a hydrolysate. These substances were present in equimolecular amounts. Moreover, they found that the corneal mucopolysaccharide was a substrate for enzyme preparations having hyaluronidase activity, and they therefore suggested that it was a natural sulphuric acid ester of hyaluronic acid. The optical rotation was in keeping with this hypothesis, and they called the corneal mucopolysaccharide hyaluronosulphate.

Wislocki, Bunting \& Dempsey (1947) found that the intensity of metachromasia in sections of cornea stained with toluidine blue was not reduced by treatment of the sections with hyaluronidase, but drew no conclusions from the observation. In a further paper (Dempsey, Bunting, Singer \& Wislocki, 1947), they described the basophilia-pH curve of various tissues containing mucopolysaccharides. That of the cornea resembled those for tissues containing hyaluronic acid, in having the basophilia suppressed at $\mathrm{pH}$ 4. As an interpretation they suggested that the ester-S groups were not ionized in the intact tissue, or that they were absent from the mucopolysaccharide.

Werner \& Odin (1949) analysed by paper chromatography a mucin from the aqueous extract, and an acid mucopolysaccharide obtained from the water-insoluble residues of cornea. Both preparations contained glucosamine, glucuronic acid, galactose, mannose and ester-S. Glucose was present in the digest from the aqueous residues but not in the mucin. They suggested that the cornea contains both a neutral and an acid mucopolysaccharide. It is difficult to evaluate their results as it is apparent that neither of their preparations was homogeneous and, although they suggested a progressiveliberation of monosaccharide residues on acid hydrolysis, they did not report the position on their chromatograms of products of partial hydrolysis.

Evidence for the inactivity of hyaluronidase in the cornea was offered by Woodin (1950a), who found that enzyme preparations from several sources were without action as spreading factors, even under artificial conditions chosen to facilitate diffusion.

In this investigation, the stages in the extraction and purification of the mucopolysaccharide have been followed by a chemical and electrophoretic analysis in an attempt to determine the way in which the mucopolysaccharide is combined in the intact tissue. The action of hyaluronidase on the mucoids and mucopolysaccharide has been investigated, and a preliminary analysis of the mucopolysaccharide by paper chromatography has been attempted. Evidence so obtained shows that the corneal mucopolysaccharide cannot be described as a sulphuric acid ester of hyaluronic acid. It has been found further that the mucopolysaccharide is capable of forming complexes with proteins present in the tissues and it appears that, in situ, the mucopolysaccharide is in combination with proteins of the collagen group.

\section{METHODS}

\section{Analytical methods}

The analysis figures given in this paper refer to the dry, ashfree, material. The ash content of solids was determined after incineration with $\mathrm{H}_{2} \mathrm{SO}_{4}$. When solutions were analysed they were dialysed against $0.001 \mathrm{~N} \cdot \mathrm{HCl}$ and subsequently against distilled water. The dry weight was then determined by drying at $100^{\circ}$ and it was assumed to be ash-free. In some cases this was confirmed by ashing.

Total nitrogen. Kjeldahl digestion for $8 \mathrm{hr}$. with a selenium catalyst was followed by distillation in the Markham still. The distillate was collected in $0.01 \mathrm{~N}-\mathrm{Ba}(\mathrm{OH})_{2}$ and titrated against $0.01 \mathrm{~N}-\mathrm{HCl}$ with a mixed methylene blue-methyl red indicator. 
Ester sulphate was determined by the gravimetric procedure of Lugg (1938) after hydrolysis in $5.8 \mathrm{~N}-\mathrm{HCl}$ at $100^{\circ}$ for $20 \mathrm{hr}$.; about $10 \mathrm{mg}$. of $\mathrm{BaSO}_{4}$ were weighed and duplicates differed by $10 \%$.

Hexosamine. This was determined by the modified ElsonMorgan reaction described by Pirie (1949). In the condensation reaction with acetyl-acetone the necks of the tubes were cooled with running water. Analytical figures given here refer to all the material which reacts with the Elson-Morgan reagents. In the early stages of this work, reported by Woodin $(1950 b)$, glucosamine standards were incorporated after the hydrolysis, but Ogston \& Stanier (1950) have shown that glucosamine is destroyed when it is heated in acid solution and this result has been confirmed here. All results reported in this paper were obtained from standards which had been put through the hydrolysis procedure given to the corneal material.
pH 4-5 with $\mathrm{Ba}(\mathrm{OH})_{8}$, and evaporated to dryness. About $300 \mu \mathrm{g}$. of the neutralized hydrolysate were added to the chromatogram. In some cases the neutralized hydrolysate was treated with ion-exchange resins before being added to the papers. Zeo-Karb 215 and De-acidite $\mathrm{E}$ were ground to a 40 -mesh powder and $20 \mathrm{ml}$. wet vol. of each put into columns. The resins were washed and then regenerated with $\mathrm{HCl}$ and $\mathrm{NH}_{4} \mathrm{OH}$, respectively. The neutralized hydrolysate was diluted and $3 \mathrm{ml}$., containing $6 \mathrm{mg}$. of solid, pressed into the column. The non-absorbed sugars were washed out with $20 \mathrm{ml}$. water. A standard solution of galactose, glucosamine, and glucurone was put through the columns as a control.

When the amino-acid composition of the mucoids was required, they were hydrolysed in $6 \mathrm{~N}-\mathrm{HCl}$ for $12 \mathrm{hr}$. and the acid removed in vacuo. Two-dimensional chromatograms were run in phenol- $\mathrm{NH}_{3}-\mathrm{KCN}$ and in collidine. They were developed with ninhydrin.

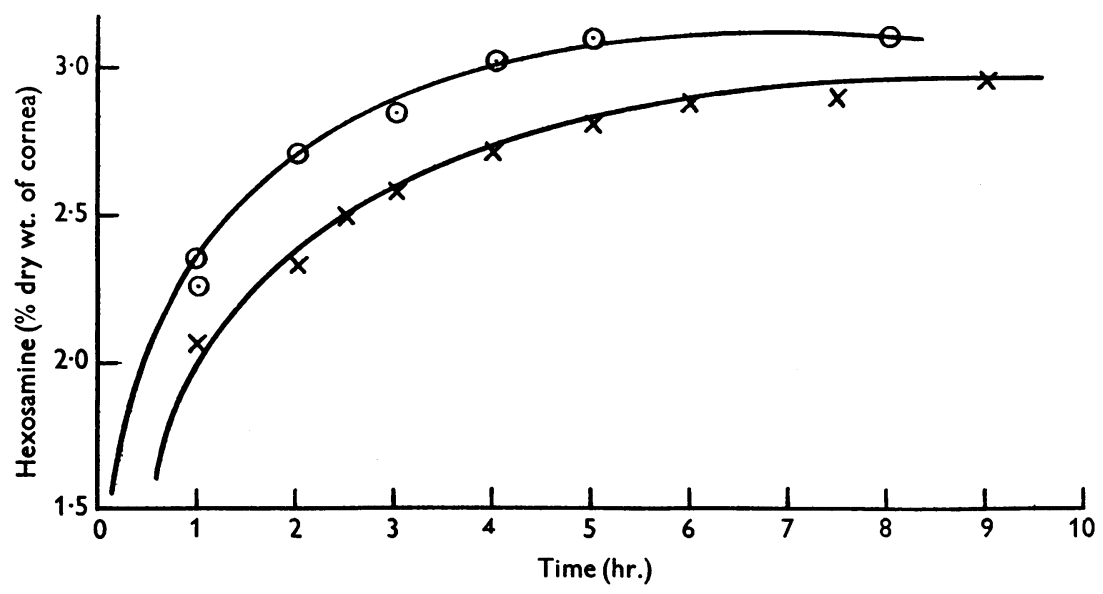

Fig. 1. Liberation of hexosamine from cornea on acid hydrolysis. $\odot, 5 \cdot 8 \mathrm{~N}-\mathrm{HCl} ; \times, 3.48 \mathrm{~N}-\mathrm{HCl}$.

Fig. 1 shows the rate at which hexosamine is liberated from the cornea on acid hydrolysis. As a routine method the corneal material was hydrolysed in $5 \cdot 8 \mathrm{~N} \cdot \mathrm{HCl}$ for $6 \mathrm{hr}$. at $100^{\circ}$.

\section{Electrophoresis}

This was done in the Tiselius apparatus at $+2^{\circ}$ with the optical system of Philpot (1938). The conductivity of the buffer solutions was measured at $0^{\circ}$. The $\mathrm{pH}$ was measured at $0^{\circ}$ by a glass electrode calibrated against $0.05 \mathrm{M}$-phthalate buffer, $\mathrm{pH} 4 \cdot 0$. To reduce boundary anomalies and viscosity effects, solutions containing a high concentration of salt and a low concentration of colloid were used. The corneal material was dialysed against a buffer containing $\mathrm{NaCl}$ $(I \mathrm{NaCl} 0 \cdot 18, I$ buffer $0 \cdot 02)$ and then the solution diluted to give a refractive increment of $0.75 \times 10^{-3}$.

\section{Chromatography on filter paper}

The techniques and purification of solvents were those described by Partridge (1948a). The chromatograms were developed with aniline hydrogen phthalate (Partridge, 1949), the Elson-Morgan reagents (Partridge, 1948a) and with the $\mathrm{AgNO}_{8}-\mathrm{KOH}$ reagent (Trevelyan, Proctor \& Harris, 1950). The mucopolysaccharide was hydrolysed in $\mathrm{N}-\mathrm{H}_{2} \mathrm{SO}_{4}$ for $6 \mathrm{hr}$. or in $5 \mathrm{~N}-\mathrm{H}_{2} \mathrm{SO}_{4}$ for $5 \mathrm{hr}$. The hydrolysates were brought to

\section{Ionophoresis on filter paper}

The apparatus described by Durrum (1950) was constructed and a ' power pack' used as the source of the current. Samples of the hydrolysate and of the standard sugars were put in line along the centre of a sheet of filter paper and the sheet draped over a glass rod with the line of spots as the apex. The apex was $25 \mathrm{~cm}$. above the level of the electrolyte. A potential of $400-600 \mathrm{~V}$. was then applied across the paper. After drying, the papers were developed with the aniline hydrogen phthalate, or the $\mathrm{AgNO}_{3}-\mathrm{KOH}$, reagents. No interference with the developers was found with $0.01 \mathrm{~N}-\mathrm{NH}_{3}$, $0.01 \mathrm{M}-\mathrm{KH}_{2} \mathrm{PO}_{4}, \quad 0.01 \mathrm{~N}-\mathrm{Na}_{2} \mathrm{HPO}_{4}$ or $5 \mathrm{~N}$-acetic acid, as electrolyte. In some cases the hydrolysate was first run as a partition chromatogram and then, after removing the solvent and adding the electrolyte, a potential was applied at right angles to the direction in which the chromatogram had been irrigated.

\section{Hyaluronidase preparations}

The enzyme preparations have been described previously by Woodin (1950a). The activity of the corneal mucopolysaccharide as substrate for hyaluronidase was assessed by measuring the reducing power of the solutions (Hagedorn \& Jensen, 1923) after incubation with the enzyme. The solu- 
tions of the corneal material were dialysed against a phosphate buffer containing $\mathrm{NaCl}(0.11 \mathrm{~m}-\mathrm{NaCl}, 0.02 \mathrm{~m}-$ phosphate) before incubation. The $\mathrm{pH}$ of the buffer was $4: 6,5 \cdot 5$, 7.0, respectively, when testis, $\mathrm{Cl}$. welchii, and streptococcal hyaluronidase, was used. The concentration of the corneal mucoids and mucopolysaccharide was deduced from the hexosamine content of the dialysed solutions.

\section{Test of enzyme digestion}

The dialysed substrate solution $(2 \mathrm{ml}$.) was put in tubes and $0.1 \mathrm{ml}$. of the enzyme added. The mixed solution $(0.5 \mathrm{ml}$.) was immediately withdrawn and added to the Hagedorn-Jensen reagent. The rest of the solution was incubated at $37^{\circ}$ (see Table 5) and then $0.5 \mathrm{ml}$. withdrawn and added to the Hagedorn-Jensen reagent.

A crude preparation of hyaluronic acid from ox vitreous filtrate was digested in parallel. The filtered vitreous was precipitated with 3 vol. of acetone containing $3 \%$ acetic acid, and the precipitate collected, suspended in water, and dialysed. The insoluble material was rejected and the supernatant precipitated again with acid acetone. The precipitate was then dried. After dialysis against the appropriate buffer, the concentration of the hyaluronic acid was determined from the hexosamine liberated after hydrolysis in $5 \cdot 8 \mathrm{~N}-\mathrm{HCl}$ for $6 \mathrm{hr}$. at $100^{\circ}$.

\section{Viscosity measurements}

These were made at $25^{\circ}$ in an Ostwald viscosimeter having a flow time of 20 sec. for $3 \mathrm{ml}$. water. The corneal mucoids were dialysed against a phosphate- $\mathrm{NaCl}$ buffer at

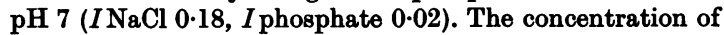
the solutions was determined from their nitrogen content. For each substance investigated, a curve was constructed relating the concentration to the log. of the relative viscosity. This relationship was linear and in the section describing the results the viscosity of the mucoids will be given as $\log \eta_{\text {rel. }}$ for a $0.5 \%$ solution.

\section{Preparation of material}

The corneas were cut from ox eyes 2-3 hr. after the death of the animal, rinsed in distilled water, and frozen into blocks. They were then cut to $20 \mu$. sections on the freezing microtome. The sections could then be dried by sublimation, or by acetone, or could be extracted directly.

\section{Extraction of the cornea}

In general a known weight of the sections (of which the dry weight and ester-S content was known) was suspended in the solvent using about $25 \mathrm{ml}$. for each gram, dry weight, of the sections. The suspension was brought to $\mathrm{pH} 8$, left for 3-4 days at $0^{\circ}$, and then centrifuged and the residues extracted again twice. Finally the residues were dialysed till free from $\mathrm{Cl}^{-}$and their dry weight and ester-S content determined.

\section{Sulphatase activity}

If the extraction experiments were to be of value, it was important to know whether the corneal sections had a sulphatase activity. $1 \mathrm{~g}$. sections, dried by sublimation, was suspended in water, the $\mathrm{pH}$ of the suspension being 6.7 , and then incubated at $37^{\circ}$ in the presence of toluene for $24 \mathrm{hr}$. A further sample was heated to $100^{\circ}, 25 \mathrm{ml}$. of boiling water added and the suspension kept at $100^{\circ}$ for 15 min., then cooled and incubated at $37^{\circ}$ for $24 \mathrm{hr}$. At the end of the incubation period the tubes were filtered, the filtrates acidified and the mucin was centrifuged off. $0.5 \mathrm{M}-\mathrm{BaCl}_{2}$ (1 ml.) was then added to $15 \mathrm{ml}$. of the supernatant. A visible precipitate of $\mathrm{BaSO}_{4}$ was produced in each case, but neither weighed more than $200 \mu \mathrm{g}$.

\section{RESULTS}

Composition of the cornea. The sections of cornea, after washing in acetone, contained $0 \cdot 25-0.26 \%$ ester-S and $3 \cdot 00-3 \cdot 25 \%$ hexosamine. The ester-S corresponds to a mucopolysaccharide content of $4.2 \%$. On the basis of their final yield, Meyer \& Chaffee (1940) gave the mucopolysaccharide content of the cornea as $1.8 \%$. Only $54 \%$ of the hexosamine of the cornea is accounted for as a component of the mucopolysaccharide. Under the conditions of the test, the corneal sections had no sulphatase activity. The inorganic sulphate in the cornea represents less than $5 \%$ of the ester sulphate.

Extraction of the mucoids from cornea. Meyer \& Smyth (1937) used $10 \%$ calcium chloride to extract acid mucopolysaccharides from connective tissues. Partridge (1948b) obtained good yields of chondroitin sulphate by extracting cartilage with $10 \%$ calcium chloride. Extraction with sodium chloride at pH 8 is the basis of the Bergman \& Stein (1939) method of preparing collagen and was used by Pirie (1947) to free corneal collagen from the ground substance. These methods have been compared

\section{Table 1. Extraction of cornea at $\mathrm{pH} 8$}

(Where sections were extracted successively by different solvents the amount of mucoid dissolved, given in column 3, is the percentage of that initially present in the intact tissue. The amount in the residues is that remaining after extraction with all solvents.)

\begin{tabular}{|c|c|c|c|}
\hline $\begin{array}{l}\text { Nature of } \\
\text { sections }\end{array}$ & Solvent & $\begin{array}{l}\text { Ester-S } \\
\text { dissolved } \\
(\%)\end{array}$ & $\begin{array}{l}\text { Ester-S in } \\
\text { residues } \\
(\%)\end{array}$ \\
\hline Dry & $10 \% \mathrm{CaCl}_{2}$ & 45-50 & $0 \cdot 2$ \\
\hline Wet & $10 \% \mathrm{CaCl}_{2}$ & $60-65$ & $0 \cdot 1$ \\
\hline Wet & $\begin{array}{l}\text { (a) } 10 \% \mathrm{NaCl} \\
\text { (b) } 10 \% \mathrm{CaCl}_{2}\end{array}$ & $\begin{array}{l}40 \\
30\end{array}$ & $\overline{0.09}$ \\
\hline Wet & $\begin{array}{l}\text { (a) Water } \\
\text { (b) } 10 \% \mathrm{NaCl} \\
\text { (c) } 10 \% \mathrm{CaCl}_{2}\end{array}$ & $\begin{array}{l}20 \\
30 \\
35\end{array}$ & $\frac{\bar{z}}{0.05}$ \\
\hline Swollen & $10 \% \mathrm{CaCl}_{2}$ & 85 & 0.06 \\
\hline
\end{tabular}

here. Initially the tissue was dehydrated with acetone to denature water-soluble proteins, but it has been found that drying the tissue reduces the efficiency of the extraction. A better yield was obtained from sections which had not been dried. The most efficient extraction was from sections which had swollen in water to give a wet weight/dry weight ratio of 32 .

The results of the extraction experiments are given in Table 1 . The same efficiency of extraction of 
dry sections was found whether drying was by acetone at room temperature or at $-10^{\circ}$, or by sublimation. Heating the sections at $45^{\circ}$ for $30 \mathrm{~min}$. (Partridge, 1948b) did not increase the yield of mucoid.

More mucoid could be dissolved from the residues after extraction at $\mathrm{pH} 8$ by heating them at $37^{\circ}$ and pH 11 for 30 min. Although a mucoid rich in ester-S could be recovered by fractionation of this extract, the residues from the extraction at $\mathrm{pH} 8$ and at pH 11 contained the same amount of ester-S. It appears that protein and mucopolysaccharide are dissolved to the same extent at $\mathrm{pH} 11$. ethanol at $-10^{\circ}$. These substances will be called the 'insoluble mucoids', and the 'soluble mucoids', respectively. The insoluble mucoids were washed with water and the suspension frozen and dried by sublimation. The soluble mucoids were dissolved in water and dried by sublimation.

We shall be concerned with the extracts made from acetone-dried sections, from water-swollen sections, and from the residues remaining after extraction of the sections with water. Only the extracts made in calcium chloride solution have been studied to any extent. The soluble mucoids and the insoluble mucoids will be described separately. The soluble

Table 2. Composition of corneal extracts

(1) Extract made in distilled water

(2) Direct precipitation with 3 vol. ethanol and $0.5 \%$ sodium acetate of extract made in $10 \% \mathrm{CaCl}_{2}$ :

From dry sections $\mathrm{pH} 8$

From fresh sections pH 8

From fresh sections $\mathrm{pH} 8$ with heat treatment

From fresh sections pH 11.(after pH 8 extraction)

(3) Water-soluble mucoids prepared by 1 vol. ethanol precipitation of dialysed $\mathrm{CaCl}_{2}$ extract, $\mathrm{pH} 8$ :

From dry sections

From swollen sections

From water-extracted sections

(4) Water-soluble mucoids from dialysed $\mathrm{CaCl}_{2}$ extract, not fractionated with ethanol:

From dry sections

$\begin{array}{ccc}N & \begin{array}{c}\text { Ester-S } \\ (\%)\end{array} & \begin{array}{c}\text { Hexosamine } \\ (\%)\end{array} \\ 13 \cdot 1 & 0.53 & 7.3 \\ & & \\ 13.4 & 0.70 & 8.8 \\ 12 \cdot 3 & 0.70 & 9.0 \\ 14 \cdot 6 & -5.5 \\ 14.8 & 0.80 & 5.0 \\ & & \\ 11.5 & & 11.4 \\ 11.4 & 1.1 & 11.7 \\ 11.2 & 2.1 & 12.7 \\ & & \\ 12.2 & & 8.2\end{array}$

Table 3. Electrophoresis of soluble mucoids

(The refractive increment of the solution was about $0.75 \times 10^{-8}$ in a buffer of composition $I \mathrm{NaCl} 0 \cdot 18, I$ buffer $0 \cdot 02$. A current of 0.01-0.02 amp. was passed for 6-8 hr.)

\begin{tabular}{ll}
\multicolumn{1}{c}{ Origin } & pH \\
Dry sections & $9 \cdot 05$ \\
& $6 \cdot 80$ \\
Swollen sections & $6 \cdot 8$ \\
& $4 \cdot 7$ \\
Water-extracted sections & $6 \cdot 8$
\end{tabular}

Fractionation of the extracts. In the earliest stages of this work the extracts were precipitated directly with 3 vol. ethanol and sufficient sodium acetate to give a final concentration of $0.5 \%$. The solid obtained had a high ash content and was only partly soluble in water and dilute salt solutions; moreover, it gave unsatisfactory results when fractionated by the methods described below. The composition of the products of direct precipitation is given in Table 2.

Subsequently, the extracts made in salt solutions - were dialysed against running tap water and then against distilled water. A precipitate appeared during the dialysis and material remained in solution which could be recovered by the addition of 1 vol. of

Contribution of
fastest to total
refraction
$(\%)$
60
62
50
50
62

Hexosamine/nitrogen
ratio of fastest
component
1.3
1.3
1.4
-
2.5

mucoids account for $85 \%$ of the total amount of ester sulphur extracted from the swollen sections, and for $80 \%$ of the total extracted from the dry sections. Fig. 2 summarizes the fractionation procedures described below.

\section{The soluble mucoids}

The composition of the soluble mucoids is given in Table 2. Solutions of the soluble mucoids were examined in the Tiselius apparatus since it was hoped to prepare a protein-free preparation of the mucopolysaccharide by the electrophoretic method. However, as Table 3 indicates, the fast components of the mucoids always contain considerable amounts 
of protein. The mobility of the slowest component was very low and these results are not evidence for its homogeneity. represent part of the water-soluble proteins of the cornea. They are absent from the extract from dry sections, perhaps because of denaturation by the

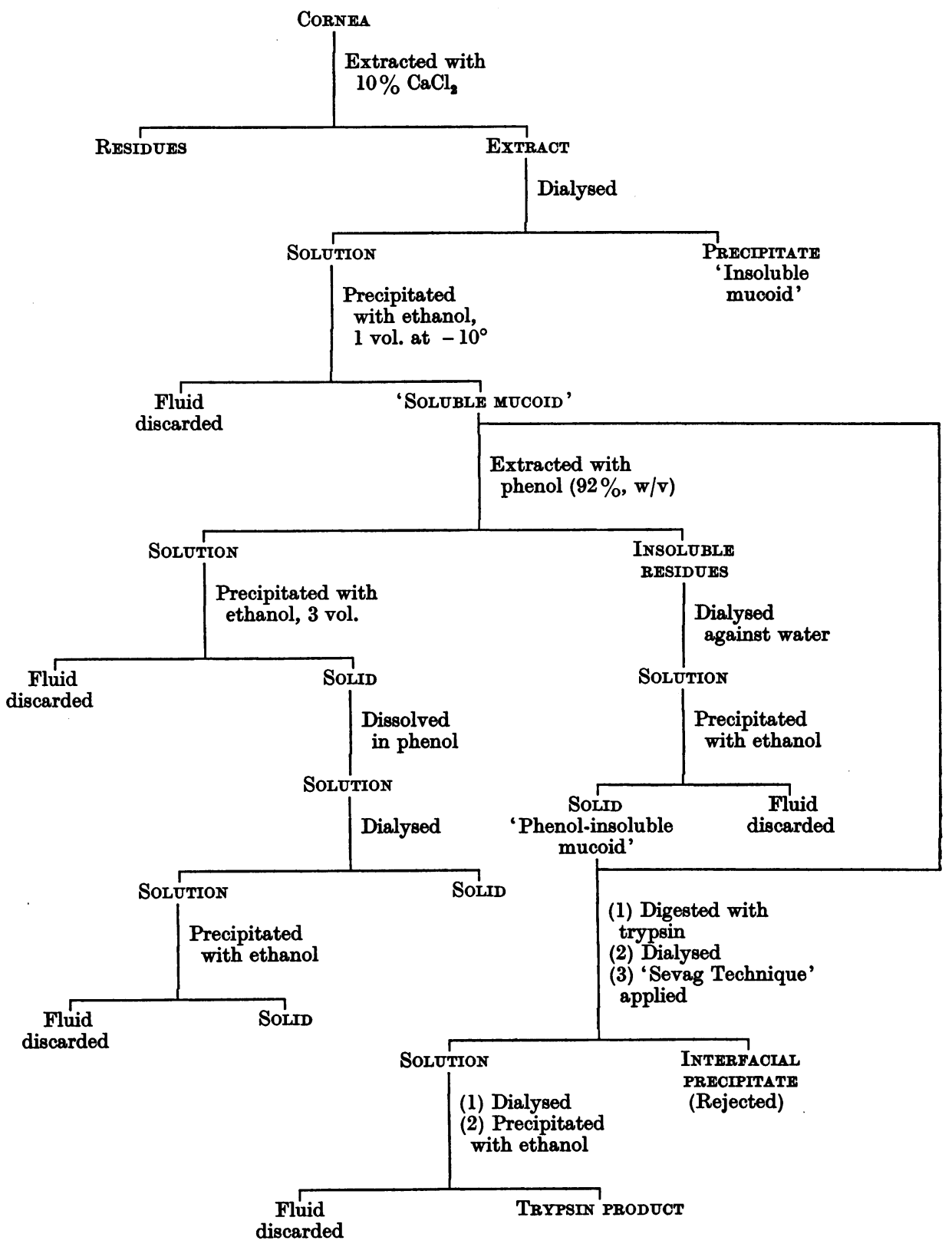

Fig. 2. Diagram of fractionation procedure.

At $\mathrm{pH} \mathrm{4.7}$ the fast component of the soluble mucoids from the swollen sections contained $11.0 \%$ nitrogen and the other components contained $12.0 \%$ nitrogen. The two components of intermediate mobility present in this extract probably acetone, and from the soluble mucoids from the aqueous residues because of the preliminary water extraction. Preliminary experiments on the watersoluble fraction of the corneal proteins support this suggestion. The aqueous extract had four com- 
ponents at $\mathrm{pH} 6 \cdot 8$, the fastest being responsible for $20 \%$ of the total refraction and having a mobility of the same order as that of the soluble mucoids from dry and swollen sections. When the aqueous extract was precipitated with 3 vol. of ethanol and $0.5 \%$ sodium acetate at $-10^{\circ}$, the precipitate did not dissolve when suspended in water and dialysed.

The mobilities of the fast components of the mucoids is given in Table 4.
The phenol-insoluble fraction from dry sections separated into two components on electrophoresis at $\mathrm{pH}$ 's 6.8 and 3.97. The slow component represented $25 \%$ of the total refraction, of which an unknown amount was due to the 'boundary anomalies'. The slow component was not identical with the phenol-soluble fraction of the soluble mucoids since it persisted through successive phenol extractions and ethanol precipitations. A sample

Table 4. Electrophoretic mobilities of fast components of the mucoids

(The electrolyte had the composition $I \mathrm{NaCl} 0 \cdot 18, I$ buffer 0.02 . The mobilities are means from both limbs.)

\section{Origin}

Soluble mucoids from acetone-dried sections

Soluble mucoids from swollen sections

Soluble mucoids from water-extracted residues

Aqueous extract

Phenol-insoluble mucoid from acetone-dried sections

Phenol-insoluble mucoid from swollen sections

Phenol-insoluble mucoid from water-extracted residues

Trypsin product from dry sections

Trypsin product from swollen sections

Trypsin product from aqueous residues

\section{Extraction of the soluble mucoids with phenol}

That polysaccharides can be separated from proteins by extraction with phenol was first shown by Morgan \& Partridge (1941), for mucoids of bacterial origin. Phenol has subsequently been used to reduce the protein content of mucoids from connective tissues (Rogers, 1945; Partridge, 1948b). When the soluble mucoids from all three types of corneal sections were extracted with $92 \%(w / v)$ phenol at room temperature, a separation was achieved into a fraction soluble in phenol and one insoluble in phenol.

\section{Phenol-insoluble fraction}

The insoluble fraction was suspended in water and dialysed, when it gave an opalescent solution. A solid was precipitated by the addition of 2 vol. of ethanol, redissolved in water and dried by sublimation. The solid was extracted again with phenol, dialysed, precipitated with ethanol, dialysed, and dried by sublimation. So prepared, the phenolinsoluble material had the composition:

From dry sections: $8.0 \% \mathrm{~N}, 18.4 \%$ hexosamine, $\mathbf{3 . 6} \%$ ester-S.

From swollen sections: $8.3 \% \mathrm{~N}, 19.0 \%$ hexosamine.

From water-extracted sections: $8.7 \% \mathrm{~N}, 21.0 \%$ hexosamine.

\begin{tabular}{|c|c|c|}
\hline Buffer & $\mathrm{pH}$ & $\begin{array}{c}\text { Mobility } \\
\mu . \times 10^{5}\left(\mathrm{~cm}^{2} \text { sec. }^{-1} \mathrm{~V} .-1\right.\end{array}$ \\
\hline $\begin{array}{l}\text { Glycine } \\
\text { Phosphate }\end{array}$ & $\begin{array}{l}9 \cdot 05 \\
6 \cdot 80\end{array}$ & $\begin{array}{l}-7.6 \\
-7.4\end{array}$ \\
\hline $\begin{array}{l}\text { Phosphate } \\
\text { Acetate }\end{array}$ & $\begin{array}{l}6 \cdot 80 \\
4 \cdot 7\end{array}$ & $\begin{array}{l}-7 \cdot 8 \\
-7 \cdot 2\end{array}$ \\
\hline Phosphate & 6.82 & $-9 \cdot 12$ \\
\hline Phosphate & $6 \cdot 80$ & $-8 \cdot 05$ \\
\hline $\begin{array}{l}\text { Phosphate } \\
\text { Acetate }\end{array}$ & $\begin{array}{l}6.90 \\
3 \cdot 97\end{array}$ & $\begin{array}{l}-9 \cdot 0 \\
-8 \cdot 6\end{array}$ \\
\hline Phosphate & $6 \cdot 25$ & $-9 \cdot 2$ \\
\hline Phosphate & $6 \cdot 82$ & $-9 \cdot 4$ \\
\hline Phosphate & 6.80 & $-9 \cdot 25$ \\
\hline Phosphate & $6 \cdot 64$ & $-9 \cdot 4$ \\
\hline Phosphate & 6.62 & $-9 \cdot 4$ \\
\hline
\end{tabular}

was isolated and found to contain about 5-10\% hexosamine. The phenol-insoluble material from the swollen sections contained a small amount of this slow component, but the phenol-insoluble material from the water-extracted sections contained less than $2 \%$ of a slow-moving component.

The fast components of these phenol-insoluble mucoids had similar mobilities (see Table 4), and a Hexosamine/Nitrogen $(\mathrm{H} / \mathrm{N})$ ratio of $2 \cdot 5-3 \cdot 0$. A $0.5 \%$ solution of the fast component of the phenolinsoluble material from the dry sections had $\log \eta_{\text {rel. }}=0 \cdot 28$.

The amino-acid composition of the phenolinsoluble mucoid from the water-extracted residues was determined by paper chromatography. The presence of glycine, alanine, proline, hydroxyproline, glutamic and aspartic acids, arginine, lysine, valine, serine and threonine, and an area corresponding to phenylanaline and the leucines could be demonstrated. These amino-acids are those shown to be present in collagen by Bowes \& Kenten (1949).

The results described above refer to mucoids obtained by extraction with calcium chloride solutions. When the water-insoluble residues of the cornea were extracted with $10 \%$ sodium chloride, pH 8, water-soluble mucoids were obtained with $1.9 \%$ ester-S. This, at pH 6.8 , had a fast component in the Tiselius apparatus which was responsible for 
$55 \%$ of the total refraction. When the dry mucoids were extracted with $92 \%$ phenol, the nitrogen content of the insoluble fraction could not be reduced below $8.0 \%$. It is hence unlikely that the association between the polysaocharide and the protein in the corneal extracts is due to a specific action of the $\mathrm{Ca}^{++}$ion.

\section{Phenol-soluble fractions}

The first phenol extract of the soluble mucoids gave a precipitate on addition of 3 vol. of ethanol, but only a slight turbidity was obtained from the similar to that of the phenol-insoluble fraction and it would appear that both are derived from corneal collagen.

\section{Treatment of the phenol-insoluble material with} chloroform and amyl alcohol

An attempt was made to reduce the protein content of the phenol-insoluble mucoid by the 'Sevag' technique. $0.3 \%$ solutions of the phenol-insoluble material from dry sections were made in $0.25 \mathrm{M}-\mathrm{NaCl}, \mathrm{pH} 4 ; 0.25 \mathrm{M}-\mathrm{NaCl}, \mathrm{pH} 8$; and $10 \% \mathrm{CaCl}_{2}, \mathrm{pH} 8$, and each was shaken with a mixture of 4 vol. of chloroform and $1 \mathrm{vol}$. amyl alcohol. The interfacial precipitate from the successive shakings was collected, and

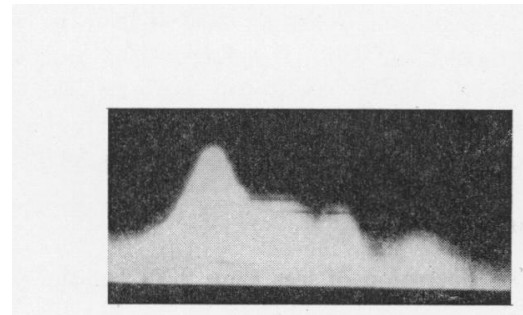

(a)

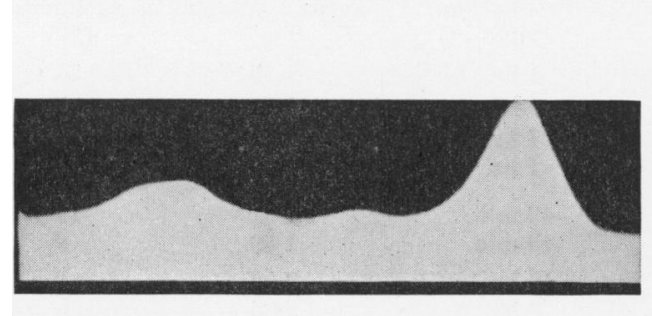

(d)

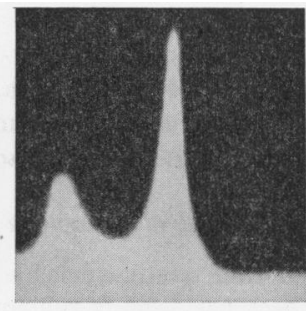

(b)

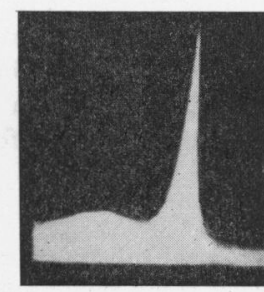

(c)

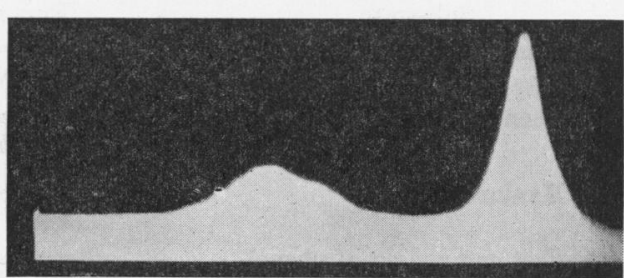

(e)

Fig. 3. Electrophoretic diagrams of corneal extracts. In all cases the buffer had the composition $I \mathrm{NaCl} 0 \cdot 18, I$ buffer 0.02. The photographs have been taken with the slit at a high angle and are of the descending limbs with migration

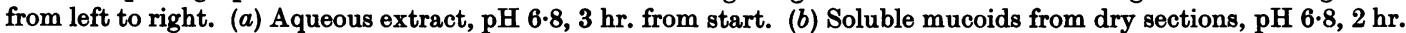
from start. (c) Phenol-insoluble mucoids from swollen sections, $\mathrm{pH} \mathrm{6.8,} \mathrm{2.5} \mathrm{hr.} \mathrm{from} \mathrm{start.} \mathrm{(d)} \mathrm{Soluble} \mathrm{mucoids}$

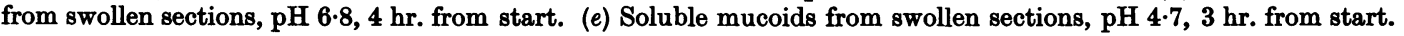

second phenol extract. The solid precipitated from the phenol solution was dried and dissolved again in phenol. Dialysis of this solution against water gave a precipitate and a solution from which material was precipitated by the addition of $2 \mathrm{vol}$. of ethanol.

The solid produced by the addition of ethanol to the phenol extract of the soluble mucoids from the dry sections contained $0.25 \%$ ester-S, $2 \cdot 6 \%$ hexosamine, $13 \%$ nitrogen. The solid precipitated during the dialysis of the phenol extract of the soluble mucoid from the water-extracted sections contained $14.8 \%$ nitrogen. The water-soluble, phenol-soluble, fraction of the same origin had a $\mathrm{H} / \mathrm{N}$ ratio of $\mathbf{1 \cdot 4}$.

The hydrolysate of the phenol-soluble, waterinsoluble fraction derived from the water-insoluble residues of cornea had an amino-acid composition washed with distilled water by centrifugation, till the supernatant was free from $\mathrm{Cl}^{-}$. The precipitate contained 7.5-8.0\% $N$ (not corrected for ash content). It appeared that the phenol-insoluble mucoid was precipitated unchanged.

\section{Treatment of the mucoids with trypsin}

Solutions of the phenol-insoluble material, and of the soluble mucoids, were adjusted to $\mathrm{pH} 8$ and incubated at $37^{\circ}$ with crystalline trypsin until the $\mathrm{pH}$ remained constant. About $10 \mathrm{mg}$. of trypsin were added for every $250 \mathrm{mg}$. of hexosamine present in the mucoids. A precipitate which appeared in the digest during the incubation was centrifuged off, and the supernatant dialysed. The $\mathrm{N}$ content of the soluble material could be reduced to 4-5\% by this process. The dialysed digest was diluted to give an $0.2 \%$ solution in $10 \% \mathrm{CaCl}_{2}, \mathrm{pH} 8$, and shaken with chloroform and amyl alcohol. When no further interfacial precipitate appeared, the process was repeated at $\mathrm{pH} 4$ and the interfacial precipitate 
removed. The solution was finally dialysed against $0.001 \mathrm{~N}-$ $\mathrm{HCl}$, precipitated from the acid solution by 2 vol. ethanol, redissolved in water, dialysed, and dried by sublimation. After dialysis against 0.001 $\mathrm{N}$-HCland precipitation from the acid solution with ethanol, $10 \mathrm{mg}$. had no weighable ash so that analytical figures refer to the free acid and not to a salt.

The nitrogen content of the 'trypsin products' varied between $2.9 \%$ and $4.0 \%$, and an electrophoretic examination revealed that they were not homogeneous. Preparations from all three types of corneal section had a fast-moving component and a material of very low mobility. In the trypsin product from the water-extracted sections, this slow component was responsible for $25 \%$ of the refraction, and in the other products, rather more. The fast component contained $3.3 \%$ nitrogen, $35 \%$ hexosamine, and $6.2 \%$ ester-S. The fast component of the trypsin product from the dry sections had $\log \eta_{\text {rel. }}=0.14$ for a $0.5 \%$ solution.

\section{Analysis by chromatography on filter paper}

Analysis of mucopolysaccharides which contain uronic acids and hexosamines is complicated by the fact that the hydrolysis can proceed in stages with destruction of the more labile residues before all the glycosidic linkages are broken. Both degradation products and products of partial hydrolysis can be expected in the hydrolysate.

The analyses reported below were made on the fast component of the trypsin product, isolated after electrophoresis at $\mathrm{pH}$ 6.8. The same results have been obtained whatever the origin of the trypsin product. The hydrolysis conditions used have been $N$-sulphuric acid at $100^{\circ}$ for $6 \mathrm{hr}$. and $5 \mathrm{~N}$-sulphuric acid at $100^{\circ}$ for $6 \mathrm{hr}$. The polysaccharide yielded $78 \%$ reducing substances (as glucose) after the hydrolysis with $5 \mathrm{~N}$ acid; with the $\mathrm{N}$ acid hydrolysate the reducing power was $38 \%$. It

\section{Table 5. Hydrolytic action of hyaluronidase}

(All the corneal substrates were derived from acetone-dried sections. The liberation of less than $2.5 \%$ of the total reducing sugar is not significant and has been neglected in column 5.)

Substrate
Hyaluronic acid
Phenol-insoluble mucoids
Hyaluronic acid
Fast component of phenol-
insoluble mucoids
Trypsin product

\section{Action of hyaluronidase on the mucoids and mucopolysaccharide}

Table 5 gives the results of incubating the corneal extracts with hyaluronidase. The depolymerase activities of the enzyme preparations were such that $0.1 \mathrm{ml}$. of all enzymes tested disaggregated the hyaluronic acid in $2 \mathrm{ml}$. of the filtrate from ox vitreous body in less than 60 sec. That they possessed a hydrolytic activity is shown by the reducing sugars liberated from the hyaluronic acid preparation. The reducing sugar available in the hyaluronic acid preparation was calculated from the apparent hexosamine content; it is probable that hyaluronic acid is not the only substance containing hexosamine in this preparation (Pirie, 1949), and the figures given for the percentage of hydrolysis are probably too low. In calculating the percentage hydrolysis of both the hyaluronic acid and the corneal material, the assumption was made that reducing sugar equivalent to 2 equiv. of glucose was present for every equivalent of hexosemine.

$\begin{array}{ccc}\begin{array}{c}\text { Incubation } \\ \text { time }\end{array} & \begin{array}{c}\text { Reducing } \\ \text { sugar available } \\ (\mathbf{m g} .)\end{array} & \begin{array}{c}\text { Total reducing } \\ \text { sugar liberated } \\ (\%)\end{array} \\ 1 \mathrm{hr} \text {. } & 1.18 & 24 \\ 1 \mathrm{hr} . & 1.18 & 8 \\ 1 \mathrm{hr} . & 1.48 & 0 \\ 1 \mathrm{hr} . & 1.48 & 0 \\ 49 \mathrm{~min} . & 2.61 & 19 \\ 49 \mathrm{~min} . & 1.69 & 9 \\ 6 \mathrm{hr} . & 2.05 & 0 \\ 6 \mathrm{hr} . & 2.05 & 0 \\ 4 \mathrm{hr} . & 2.06 & 0 \\ 4 \mathrm{hr} . & 2.06 & 0\end{array}$

was found that all the ester-S was removed by hydrolysis in N-hydrochloric acid for $6 \mathrm{hr}$. at $100^{\circ}$, and it is presumed that sulphuric acid has the same effect.

\section{Chromatogram irrigated with collidine}

After addition of the hydrolysate and the standard sugars to the paper, $5 \mathrm{~N}$-ammonia was added to each spot and allowed to dry off at room temperature. The paper was then irrigated for $48 \mathrm{hr}$. On development, the presence of galactose, glucosamine, and galactosamine in, and the absence of glucurone and glucuronic acid from, both hydrolysates could be demonstrated unambiguously. There was also present in the $\mathrm{N}$-sulphuric acid hydrolysate, a substance which extended from the base line to a position $\mathbf{0 . 2}$ the distance moved by galactose, and which reacted with all three spraying reagents. It was absent from the hydrolysate treated with Zeo-Karb and reduced in intensity in that treated with DeAcidite. The 5N-sulphuric acid hydrolysate also contained some reducing material of low mobility 
which gave a diffuse trail from the base-line to a position $0 \cdot 3$ the distance moved by galactose.

\section{Chromatogram irrigated with phenol}

Galactose and a hexosamine were present in the $\mathrm{N}$-sulphuric acid hydrolysate, and also material of low mobility which after $36 \mathrm{hr}$. irrigation separated into two spots and reacted with all three spraying reagents. The slower spot moved $0 \cdot 15$ the distance moved by galactose and was absorbed by the ZeoKarb but not by De-Acidite. The faster moved 0.35 the distance moved by galactose and was absorbed by both resins. No amino-acids could be detected in $0.5 \mathrm{mg}$. of polysaccharide hydrolysed in $5 \mathrm{~N}$ sulphuric acid. a potential across the paper with $0.01 \mathrm{~N}$-ammonia as electrolyte. One of the slow-moving reducing substances moved to the anode.

No glucurone was present in the hydrolysate. Its absence is probably not due to destruction since a glucurone spot was found in a chromatogram from a mixture of galactose, glucurone and glucosamine, which had been put through the N-sulphuric acidhydrolysis procedure.

\section{Ionophoresis on filter paper}

After the addition of the hydrolysate, or the standard sugars, to the papers $5 \mathrm{~N}$-ammonia was added to the spots and allowed to dry off at room temperature. This was a necessary procedure to

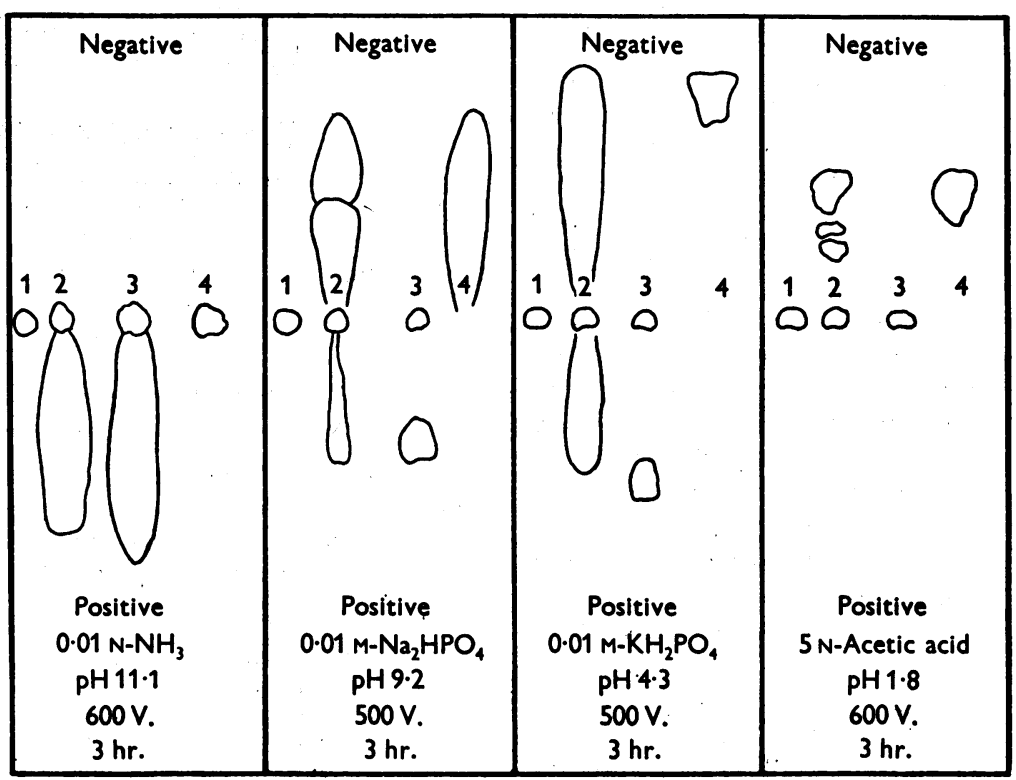

Fig. 4. Diagram of papers developed with aniline hydrogen phthalate after ionophoresis. $50 \mu \mathrm{g}$. of the standard sugars and $300 \mu \mathrm{g}$. of the hydrolysate were added to the spots. Positions are relative to galactose and not to the initial position. $\mathrm{l}=$ = Galactose; $2=\mathrm{N}-\mathrm{H}_{2} \mathrm{SO}_{4}$ hydrolysate; 3 = glucurone $+\mathrm{NH}_{3} ; 4=$ glucosamine hydrochloride.

\section{Chromatogram irrigated with butanol-acetic acid}

After $36 \mathrm{hr}$. irrigation, galactose and glucosamine were not separated. The $\mathrm{N}$-acid hydrolysate showed in addition to these substances two reducing materials, the slower moving $0 \cdot 35$ as far as galactose, and the faster 0.59 as far as galactose. The slower was removed by both resins, the faster by the ZeoKarb only. That the absorption by the De-Acidite was due to a negative charge on the molecule and not to an unspecific absorption was shown by first irrigating the chromatogram with butanol-acetic acid and then, after removal of the solvent, applying ensure the conversion of some of the glucurone to ammonium glucuronate.

The results are summarized in Fig. 4. Glucosamine is not charged at $\mathrm{pH} 11$ and glucuronic acid could not be detected in the glucurone at $\mathrm{pH} \mathbf{1 . 8}$. It is clear that there is a negatively charged sugar ion in the polysaccharide hydrolysate. Acetic acid was the only solvent in which the hydrolysate gave discrete spots on ionophoresis. In the other solvents the charged species in the hydrolysate gave pearshaped trails. The separation of the positively charged material into three spots with acetic acid as solvent is of interest; such an effect would be 
expected if the hydrolysate contained partial hydrolysis products, or degradation products, in which the hexosamine was combined with neutral or weakly acidic substances.

\section{Fractionation of the insoluble mucoids}

The composition of the insoluble mucoids obtained from dry sections by calcium chloride extraction was $15 \%$ nitrogen, $3.5 \%$ hexosamine, $0.6 \%$ ester-S. The insoluble mucoids from sodium chloride extracts had a similar composition.

At least $0.5 \%$ sodium chloride was necessary to keep the insoluble mucoid in solution. As the solutions were very viscous, even in the presence of this concentration of salt, they were not analysed electrophoretically. The insoluble mucoids cannot be digested by trypsin.

The insoluble mucoids from the dry sections were dissolved in $10 \% \mathrm{CaCl}_{2}$ and the solution precipitated with 3 vol. of ethanol and a final concentration of $0.5 \%$ sodium acetate. The precipitate contained $13.5 \% \mathrm{~N}$, and $6.0 \%$ hexosamine. The dry solid was extracted with $92 \%$ phenol solution at room temperature. The insoluble fraction was suspended in water and dialysed, when it dissolved to give an opalescent solution, from which the addition of 2 vol. of ethanol precipitated a white solid.

The ethanol precipitate contained $9 \%$ nitrogen, $17 \%$ hexosamine, and contained ester-S. A hydrolysate made in N-sulphuric acid showed glucosamine and galactose but no glucuronic acid. Moreover, this hydrolysate contained the slow-moving reducing material present in the $\mathrm{N}$-sulphuric acid hydrolysate from the trypsin product.

However, the chromatograms were not so clear as those from the trypsin product and it was not possible to demonstrate the presence of galactosamine conclusively.

\section{Phenol-soluble fraction of the insoluble mucoids}

The phenol extract of the insoluble mucoids was dialysed against water and the precipitate collected; the suspension in water was frozen and the water sublimed off; all the solid redissolved in phenol and was precipitated by 3 vol. of ethanol. This solid contained $16 \cdot 8 \%$ nitrogen.

It appeared from some of its properties that the protein component of the insoluble mucoids was derived from a collagen. It was thought that a test of this origin of the protein would be its further. degradation to gelatin. Accordingly, the solid precipitated, by dialysis, from the phenol extracts of the insoluble mucoid was suspended in distilled water (pH 5.5) and heated at $105^{\circ}$ for $4 \mathrm{hr}$. All but a small fraction dissolved to give a clear solution, which set to a gel on cooling, when the concentration was greater than about $1.5 \%$.

This protein was examined in the Tiselius apparatus. To enable comparison with the mobilities of gelatin derived from the collagen in cartilage, the buffer solutions were the same as those used by Partridge $(1948 b)$. As the mobilities were low, results of the highest accuracy would require a buffer of smaller ionic strength. The protein was not homogeneous (Fig. 5). The difference in the mobility of the components was small, but was most marked in acetate buffers in the range $\mathrm{pH} 3-5$. Table 4 gives the mobilities of the fast component; on the acid side of the isoelectric point they differ slightly from those for gelatin from cartilage.

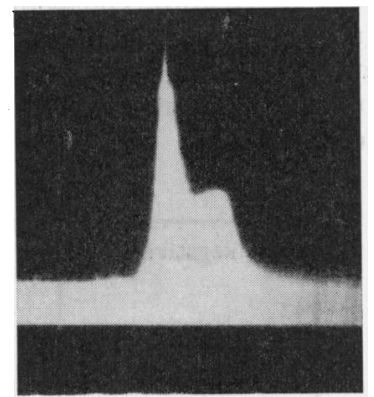

Fig. 5. Electrophoresis diagram of the gel-forming protein from the insoluble mucoids. The photograph is of the ascending limb, with migration from right to left. Acetate- $\mathrm{NaCl}$ buffer, $\mathrm{pH} \mathrm{3 \cdot 74.} 7 \mathrm{hr}$. from start, current 0.01 amp.

\section{Table 6. Electrophoretic mobilities of the gel-forming protein from the insoluble mucoid}

(The buffer contained $\mathrm{NaCl}(I \mathrm{NaCl}=0 \cdot 18, I$ buffer $=$ 0.02 ). The mobilities are the means of the values from each limb. Where the boundaries split into two peaks the mobility refers to the fast component.)

$\begin{array}{lcc}\text { Buffer } & \mathrm{pH} & \begin{array}{c}\text { Mobility } \\ \left(\mu . \times 10^{5}\right)\end{array} \\ \text { Phosphate } & \mathbf{6 . 8 0} & -1 \cdot 0 \\ \text { Phosphate } & \mathbf{6 \cdot 8 0} & -\mathbf{1} \cdot 1 \\ \text { Phosphate } & \mathbf{5 \cdot 3 4} & -0.85 \\ \text { Acetate } & \mathbf{4 . 9 2} & -0.52 \\ \text { Acetate } & \mathbf{3 \cdot 9 5} & +\mathbf{1} \cdot 28 \\ \text { Acetate } & \mathbf{3 . 7 4} & +\mathbf{1 . 4 4} \\ \text { Glycine } & \mathbf{2 . 7 5} & +\mathbf{2 . 9 5} \\ \text { Glycine } & \mathbf{2 \cdot 7 0} & +\mathbf{2 . 6 5}\end{array}$

Paper chromatography of a hydrolysate from the gel-forming proteins from cornea showed that the amino-acid composition was very similar to that of gelatin.

\section{DISCUSSION}

About $70 \%$ of the acid mucopolysaccharide has been extracted in an electrophoretically homogeneous form. The residues remaining after extraction of the swollen sections contain about $15 \%$ of the total ester-S and nothing is known about this fraction. The insoluble mucoids contain about $10-15 \%$ of the total ester-S and there is not sufficient evidence to permit identification of the carbohydrate components of the two mucoids. The 
only evidence for the homogeneity of the mucopoly saccharide is the electrophoretic measurements. The chemical fractionation was designed to remove protein and the persistence of the mucopolysaccharide through this is not evidence for its homogeneity.

The identification of galactose as a constituent of the corneal mucopolysaccharide is of interest. Suzuki (1939) considered that galactose was present but, as he used an unspecific method of identification, Meyer \& Chaffee (1940) considered that he had confused galactose and a uronic acid. I have not found a uronic acid as a constituent of the $\mathrm{N}$-acid hydrolysate of the mucopolysaccharide. However, the lability of the uronic acids and the resistance of hexosaminosides to acid hydrolysis is well known, and it is possible that its absence is due to both destruction and insufficient hydrolysis. Moreover, one of the partial hydrolysis products has an acid group and that may be due to the presence of combined uronic acid. It is probable that the identification of the uronic acid stated to be present in the corneal mucopolysaccharide will be best achieved by protection of the labile groups of the molecule before hydrolysis.

It appears from the results of Kaye \& Stacey (1951) that galactose is not a constituent of hyaluronic acid, and accordingly the suggestion of Meyer \& Chaffee (1940) that the corneal mucopolysaccharide is a sulphate ester of hyaluronic acid is invalidated by the results described in the present paper.

The mucopolysaccharide is not hydrolysed by hyaluronidase preparations. The failure of the enzyme to have a spreading action in the cornea has already been reported (Woodin, 1950a), and it was suggested in that paper that an explanation of the failure to confirm the results of Meyer \& Chaffee would be that the pneumococcal hyaluronidase used by these authors contained enzymes other than hyaluronidase. Pneumococcal infection produces a characteristic spreading ulcer in the cornea and presumably the spread is effected by enzymic processes.

The extraction experiments were designed primarily to determine the optimum conditions to bring the mucoid into solution in an undegraded form. Although a knowledge of the effect on the cornea of calcium chloride and sodium chloride in varying concentrations will be required before an explanation of these results can be offered, it is of interest that the effect of sodium chloride and calcium chloride in extracting the mucopolysaccharide from the cornea should parallel the effects of these substances in reducing the shrinkage temperature, and increasing the swelling pressure of the collagen in rat-tail tendon and in sheep skin respectively. Bowes \& Kenten (1950) have suggested that the decrease in the cohesion brought about by calcium chloride is primarily due to a reduction in the potential energy of the inter-molecular links between the polypeptide chains. The results presented here suggest that the cohesive forces of the collagen fibres and the forces holding the mucopolysaccharide to the corneal collagen are very similar. It would be of great interest to know if the mucopolysaccharide of the cornea were contributing to the cohesion of the cornea collagen, since the orderly arrangement of the collagen fibres is probably a necessary condition of the transparency of the tissue.

The corneal mucopolysaccharide can form stable complexes with proteins. The fast component of the phenol-insoluble mucoids, which contains about $40 \%$ protein, is homogeneous electrophoretically in the range $\mathrm{pH} \mathrm{8-4}$ and is resistant to chemical fractionation by the 'Sevag' technique and by extraction with phenol. The fast component of the soluble mucoids from the water-extracted residues, and the phenol-insoluble material, have the same mobility and $H / N$ ratio and they are probably identical. However, the fast component of the soluble mucoids from dry sections and from the swollen sections contains more protein than this complex; it is homogeneous in the range $\mathrm{pH} \mathrm{9.05-}$ $4 \cdot 7$, and chemical combination can be presumed to occur between the protein and mucopolysaccharide components. The mobility of this fast component is smaller than that of the phenol-insoluble material, and it is at least possible that this soluble mucoid contains a complex formed by polar association between the phenol-insoluble material and some of the water-soluble corneal proteins.

It is of interest that the proteins with which the mucopolysaccharide is associated have an aminoacid composition qualitatively the same as that of gelatin. This fact, eonsidered in conjunction with the results of the extraction experiments, suggests that the unit in the intact stroma is a mucopolysaccharide-collagen complex.

\section{SUMMARY}

1. The ester-S present in the cornea corresponds to a mucopolysaccharide content of $4 \cdot 2 \%$. There is an excess of hexosamine over that required as a constituent of the mucopolysaccharide.

2. By extraction of the water-swollen sections of cornea with $10 \%$ calcium chloride at $\mathrm{pH} 8,85 \%$ of the mucopolysaccharide can be dissolved. Extraction with calcium chloride is more efficient than extraction with sodium chloride and that is more efficient than extraction with water.

3. The mucopolysaccharide is extracted as a component of both water-soluble and waterinsoluble mucoids.

4. The protein content of the water-solublemucoids can be reduced by extraction with phenol 
to leave a phenol-insoluble mucoid. This contains a substance with the characteristics of a mucopolysaccharide-protein complex.

5. The water-soluble mucoids contain a complex which is formed by interaction between the phenolinsoluble mucoids and a water-soluble protein of the cornea.

6. The acid mucopolysaccharide can be prepared free from protein by incubation with trypsin. Galactose, glucosamine and galactosamine have been identified as constituents of the mucopolysaccharide, by chromatography and ionophoresis on filter paper.
7. The corneal mucopolysaccharide is not a substrate for hyaluronidase.

8. Gel-forming proteins have been isolated from the insoluble mucoid and found to contain the same amino-acids as gelatin, but to differ from it in their electrophoretic behaviour.

9. It is suggested that in situ the acid mucopolysaccharide is combined with proteins of the collagen group.

I wish to thank Dr A. S. McFarlane for allowing me to make the electrophoretic measurements in his laboratory and Mrs A. Dovey for much advice on the use of the instrument.

\title{
REFERENCES
}

Bergman, M. \& Stein, W. H. (1939). J. biol. Chem. 128, 217. Bowes, J. H. \& Kenten, R. H. (1949). Biochem. J. 45, 281. Bowes, J. H. \& Kenten, R. H. (1950). Biochem. J. 46, 524. Dempsey, E. W., Bunting, H., Singer, M. \& Wislocki, G.B. (1947). Anat. Rec. 98, 417.

Durrum, E. L. (1950). J. Amer. chem. Soc. 72, 2943.

Hagedorn, H. C. \& Jensen, B. N. (1923). Biochem. Z.135, 46.

Kaye, M. A. G. \& Stacey, M. (1951). Biochem. J. 48, 249.

Lugg, J. W. H. (1938). Biochem. J. 32, 2114.

Meyer, K. \& Chaffee, E. (1940). Amer. J. Ophthal. 23, 1320.

Meyer, K. \& Smyth, E. M. (1937). J. biol. Chem. 119, 507. Morgan, W. T. J. \& Partridge, S. M. (1941). Biochem. J. 35, 1140.

Morner, C. T. (1894). Hoppe-Seyl. Z. 18, 213.

Ogston, A. G. \& Stanier, J. E. (1950). Biochem. J. 46, 304.
Partridge, S. M. (1948a). Biochem. J. 42, 238.

Partridge, S. M. (1948b). Biochem. J. 43, 387.

Partridge, S. M. (1949). Nature, Lond., 164, 443.

Philpot, J. St L. (1938). Nature, Lond., 141, 283.

Pirie, A. (1947). Biochem. J. 41, 185.

Pirie, A. (1949). Brit. J. Ophthal. 33, 678.

Rogers, H. J. (1945). Biochem. J. 39, 435.

Suzuki, M. (1939). J. Biochem., Tokyo, 30, 185.

Trevelyan, W. E., Procter, D. S. \& Harris, S. S. (1950). Nature, Lond., 104, 443.

Werner, I. \& Odin, L. (1949). Uppsala LäkFören. Förh. 54, 69.

Wislocki, G. B., Bunting, H. \& Dempsey, E. W. (1947). Amer. J. Anat. 81, 1.

Woodin, A. M. (1950a). Brit. J. Ophthal. 34, 375.

Woodin, A. M. (1950b). Biochem. J. 47, xxxvii.

\section{The Synthesis of Cozymase from Nicotinic Acid and its Derivatives by Lactobacillus arabinosus 17-5}

\author{
By D. E. HUGHES AND D. H. WILLIAMSON \\ Medical Research Council Unit for Research in Cell Metabolism, Department of Biochemistry, \\ The University, Sheffield 10
}

(Received 7 November 1951)

As shown in previous papers from this laboratory (McIlwain, 1949; McIlwain, Stanley \& Hughes, 1949), glycolysis by washed suspensions of Lactobacillus arabinosus 17-5, which have been grown on a nicotinic acid-deficient medium, is stimulated by the addition of nicotinic acid. The stimulation is due to the synthesis of cozymase and, since this organism does not rapidly decompose the coenzyme (McIlwain \& Hughes, 1948), it seemed to be suitable material in which to study its synthesis. In the present studies, the effect of limiting amounts of nicotinic acid, nicotinamide and nicotinamide nucleotides on the stimulation of glycolysis and on the synthesis of cozymase has been investigated. Young deficient cells glycolysing in an optimal concentration of nicotinic acid rapidly synthesized cozymase until the cells became saturated with the coenzyme; synthesis of cozymase and metabolism of nicotinic acid then ceased. Glucose alone of the constituents of the growth medium was essential for the synthesis of cozymase by washed suspensions. The uptake of nicotinic acid ran parallel to the synthesis of coenzyme and no detectable amounts of any possible intermediate in the synthesis were detected in cells or the suspending fluid. Unexpectedly, nicotinamide was found to be rapidly deamidated by the 